\title{
NÍVEL DO DISCLOSURE AMBIENTAL DAS EMPRESAS BRASILEIRAS LISTADAS NA BM\&FBOVESPA: UMA ANÁLISE DO PERÍODO DE 2006 A 2010
}

\author{
Sheila Mendes Fernandes \\ Mestre em Ciência Contábeis pela Fucape Business School \\ sheilamenfer@gmail.com
}

\section{RESUMO}

Objetivou-se verificar, por meio deste artigo, o nível de disclosure ambiental das empresas brasileiras listadas na BM\&F Bovespa no período de 2006 a 2010. Este estudo justifica-se pela teoria do disclosure voluntário que afirma que os gestores podem optar entre o tipo de informação evidenciada aos stakeholders. Para atender ao escopo desse estudo, utilizou-se como metodologia a análise de conteúdo realizada nos relatórios da administração, nas notas explicativas e nos relatórios de informações ambientais. A pesquisa foi realizada em 154 empresas brasileiras listadas na BM\&F Bovespa. A análise dos resultados mostrou que das 198.670 sentenças encontradas apenas 8244 referiam-se ao disclosure ambiental, sendo 7502 referentes a informações ambientais positivas e 742 referentes a informações ambientais negativas, corroborando o estudo de Verrechia (2001) e Dye (2001) no qual afirmam que, com o intuito de auferir melhores resultados financeiros, os gestores optam em divulgar com mais intensidade as informações favoráveis à empresa, pois há evidências de que o mercado premia as empresas que evidenciam informações ambientais positivas e penalizam as empresas que evidenciam informações ambientais negativas.

Palavras-chave: Análise de conteúdo; Disclosure ambiental; Empresas brasileiras; Teoria do disclosure voluntário.

\section{LEVEL OF ENVIRONMENTAL DISCLOSURE OF BRAZILIAN COMPANIES LISTED ON BM \& FBOVESPA: AN ANALYSIS OF THE PERIOD 2006 TO 2010}

\begin{abstract}
This study assessed the level of environmental disclosure of Brazilian companies listed on BM\&FBovespa in the period 2006 to 2010. This study is justified by the voluntary disclosure theory which states that managers can choose the type of information shown to the stakeholders. To meet the scope of this study was used as a method of content analysis performed in the administration reports, explanatory notes and reports of environmental information. The survey was conducted on 154 enterprises classified according to Brazil (2001). The results showed that 198,670 of 8244 found only sentences referred to the environmental disclosure, and 7502 relating to environmental information regarding positive and 742 negative environmental information, corroborating the study Verrechia (2001) and Dye (2001) in which it was that in order to obtain better financial results managers choose to disclose information more heavily in favor of the company, since there is evidence that the market rewards companies that demonstrate positive environmental information and penalize companies that show negative environmental information.
\end{abstract}

Key words: Brazilian companies; Content Analysis; Environmental disclosure; Theory of voluntary disclosure. 


\section{INTRODUÇÃO}

As pesquisas que abordaram o disclosure voluntário surgiram na década de 1980, com os trabalhos seminais de Verrechia (1983) e Dye (1985). No entanto, as pesquisas sobre o disclosure voluntário começaram a se difundir com a divulgação da pesquisa de Verrechia (2001) que detalhou os modelos matemáticos dessa teoria, esse estudo ainda afirma que os objetivos das empresas é a maximização de seus índices financeiros, desse modo tendem a divulgar informações favoráveis à empresa. Quanto a essa afirmação, Dye (2001) prediz que os gestores evidenciam voluntariamente apenas informações positivas.

A literatura que aborda o disclosure ambiental concentra-se no Reino Unido, Canadá, Nova Zelândia, Austrália e Estados Unidos (Ho e Taylor, 2007). No Brasil, destacam-se os estudos de Calixto (2007); Costa e Marion (2007); Dal-Ri-Murcia et al (2008); Cunha e Ribeiro (2008); DalRi-Murcia e Santos (2009); Lima (2009); Borba, Rover e Dal-Ri-Murcia (2009); Da- Ri-Murcia et al (2010); Costa, Gallon e Torres (2011). Percebe-se um crescimento dos estudos que investigam a relação da empresa com o fator ambiental, o que possibilita que deduzir que as mudanças econômicas e financeiras influenciaram as empresas brasileiras a se adaptarem ao mercado internacional e às exigências dos shareholders, contribuindo para que a empresa buscasse ser mais transparente buscando alavancar seu valor no mercado. Outro fator, que deve ser considerado é a adoção de práticas ambientais com o intuito de reduzir custos com a eliminação e/ou redução de eventos ambientais negativos (Calixto, 2007; Borba, Rover, Dal-Ri-Murcia, 2009).

Nesse sentido, buscou-se responder o seguinte problema: Qual o nível do disclosure ambiental das empresas brasileiras listadas na BM\&FBovespa no período de 2006 a $2010 ?$

Objetivou-se verificar o nível do disclosure ambiental das empresas brasileiras listadas na BM\&Bovespa no período de 2006 a 2010. A amostra foi composta por 154 companhias classificadas de acordo com Brasil (2001). Para obter o nível de disclosure ambiental, foi utilizada como metodologia a análise de conteúdo realizada nas notas explicativas, relatório da administração e nos relatórios de informações ambientais.

Este estudo justifica-se pela continuação do debate na literatura brasileira sobre o disclosure ambiental e também para conhecer o nível de evidenciação ambiental das empresas brasileiras nos relatórios financeiros. Outra justificativa deve-se a Teoria defendida por Verrechia (1983) e Dye (1985) que expõem que os gestores podem optar entre o tipo de informação evidenciada aos stakeholders.

\section{TEORIA DO DISCLOSURE VOLUNTÁRIO}

A teoria da divulgação surgiu na década de 1980 com os trabalhos de Verrechia (1983) e Dye (1985), entretanto difundiu-se no trabalho de Verrechia (2001) que descreveu os modelos matemáticos dessa teoria, sendo distribuídos nas seguintes categorias:

- Disclosure baseado em associação - Verifica a influência da divulgação voluntária no mercado acionário.

- Disclosure baseado em julgamento - Verifica o que influência o gestor a divulgar determinada informação.

- Disclosure baseado em eficiência - Verifica qual divulgação é a preferida pelo mercado, mesmo não tendo conhecimento da informação anterior.

Segundo Salotti e Yamamoto (2005), existem custos relacionados à evidenciação, no entanto o objetivo do gestor é alavancar os resultados financeiros da empresa, desse modo o gestor divulga apenas a informação que beneficia o resultado da companhia. Por esse motivo, Verrechia (2001) e Dye (2001) encontraram evidências de que as empresas divulgam mais informações favoráveis do que as negativas. 


\subsection{Pesquisas nacionais sobre disclosure ambiental}

Buscando identificar os fatores que explicam o nível de disclosure voluntário das empresas brasileiras, Dal-Ri-Murcia e Santos (2009) analisaram as demonstrações financeiras por meio da análise de conteúdo e concluíram que as empresas maiores, pertencentes ao setor elétrico, apresentaram maior nível de disclosure voluntário, podendo, esse resultado, ser interpretado por meio do bonding hypothesis e political costs hypotheseis.

Nesse sentido, com intuito de averiguar o impacto do nível do disclosure voluntário no custo de capital de terceiros das empresas de capital aberto, Lima (2009) analisou 23 companhias brasileiras no período de 2000 a 2004 e percebeu relação inversa entre o disclosure voluntário e o custo de capital de terceiros, ou seja, à medida que aumenta o diclosure voluntário reduz a assimetria de informação entre os agentes, alavancando, desse modo, a credibilidade da companhia e gerando benefícios como, por exemplo, a redução do custo de capital de terceiros.

Dal-Ri-Murcia et al (2008), objetivando analisar o disclosure ambiental das demonstrações, estudaram o setor de alto impacto ambiental das companhias abertas brasileiras. Para tanto, utilizaram a técnica de análise de correspondência simples (Anacor) e múltipla (Homals). Em seguida, identificaram os fatores que explicam a evidenciação voluntária, por meio das técnicas estatísticas de análise fatorial e de regressão múltipla encontraram evidências estatisticamente significativas de que as variáveis: tamanho, empresas de auditoria e participação no ISE são fatores que influenciam o nível de disclosure ambiental. Nesse sentido, Borba, Rover e Dal-Ri-Murcia (2009) encontraram evidências de que predominam no mercado brasileiro as informações qualitativas do tipo positiva referentes a política ambiental, evidenciando que a divulgação ambiental voluntária reduz a assimetria de informação. Desse modo, a evidenciação de informações ambientais positivas reduz o risco de mercado da companhia influenciando a não divulgação de informações ambientais negativas.

Costa, Gallon e Torres (2011) analisaram o conteúdo dos relatórios de sustentabilidade das empresas premiadas por práticas ambientais e, em seguida, realizaram um estudo descritivo com abordagem qualitativa utilizando a técnica da análise de conteúdo para capturar o nível de disclosure ambiental. Os achados desse estudo evidenciaram que as companhias dos setores Finanças, Bens de Consumo, Energia, Papel e Celulose apresentaram os melhores níveis de evidenciação, e as empresas dos setores Siderurgia e Metalurgia, Seguros e Previdência e Informática, os piores níveis de evidenciação.

Calixto (2007) objetivou analisar as informações ambientais evidenciadas por 80 companhias de capital aberto de 17 setores brasileiros. Para obter o nível de disclosure ambiental, realizou uma análise de conteúdo nos relatórios contábeis no período de 1997 a 2005. Calixto (2007) concluiu que há nos relatórios evidenciados um aumento gradual da divulgação de informações ambientais, principalmente no relatório da administração, além disso também é possível perceber diferenças dos níveis de evidenciação entre os setores. Segundo a autora, embora tenha aumentado o nível de disclosure do período analisado, percebeu-se que algumas empresas não divulgaram qualquer informação ambiental, destacando que a visão sobre a importância da sustentabilidade é um problema cultural brasileiro.

Dal- Ri-Murcia et al (2010) revisaram a literatura internacional referente ao disclosure ambiental, para tanto, investigaram 52 periódicos de Contabilidade e Auditoria publicados em inglês e disponibilizados no website da Capes. Este estudo compreendeu o período de 1997 a 2007. Percebeu-se que os artigos predominam em mercados evoluídos, tais como Estados Unidos, Inglaterra, Canadá, Nova Zelandia e Austrália. Verificou-se ainda que o nível de disclosure ambiental varia de acordo com o país e o setor, necessitando, desse modo, de padronização do tipo e da qualidade de informação evidenciada.

Costa e Marion (2007), objetivando analisar a uniformidade das informações ambientais nos relatórios anuais do setor de papel e celulose, encontraram dificuldade em analisar o disclosure 
ambiental, uma vez que não existe padronização do tipo de informação evidenciada, sendo, em sua maioria, textos dissertativos, o que dificulta que sejam analisados, além de evidenciar a baixa qualidade da informação divulgada. Outro aspecto destacado é que poucas empresas com imposição dos stakeholders, elaboraram o balanço social objetivando melhorar a evidenciação dos impactos ambientais.

Cunha e Ribeiro (2008) investigaram os incentivos das empresas de capital aberto em divulgar voluntariamente informações de natureza social. A pesquisa foi feita no período de 2003 a 2006. As evidências empíricas mostraram que o tamanho da companhia influencia positivamente o disclosure socioambiental, outras variáveis foram analisadas como endividamento, nível de divulgação e governança, essas variáveis, portanto, não foram significativas para o modelo.

\subsection{Pesquisas internacionais sobre disclosure ambiental}

Alrazi, Sulaiman e Ahmad (2009) analisaram o relatório anual de 96 companhias da Malásia do período em 1999, 2003 e 2006. Perceberam um aumento do número de relatórios divulgados pelas companhias e uma crescente divulgação de informações sociais, evidenciando a intenção da empresa em construir uma boa imagem, denominada pela life cycle theory como "boa empresa cidadã”, no entanto, percebeu-se que não houve crescimento do disclosure ambiental, dessa forma, não se pode concluir que as informações ambientais de cada ano são informadas aos stakeholders.

Clarkson et al (2006) analisaram a relação entre a performance ambiental e o disclosure ambiental de 191 empresas americanas. Como base para a pesquisa, utilizaram a teoria do disclosure voluntário, defendida por Verrechia (2001) e Dye (2001). Para obter o nível do disclosure voluntário, realizaram análise de conteúdo no Global Reporting Initiative (GRI). Encontraram indícios de que o desempenho ambiental está estatisticamente relacionado ao disclosure ambiental.

Manurung e Basuki (2010) investigaram, por meio de uma análise empírica, os relatórios de sustentabilidade das companhias do Reino Unido e dos Estados Unidos no período de 2006 a 2008. Nessa investigação, perceberam um crescente aumento de informações socioambientais evidenciadas, em que foi possível destacar também que as informações são evidenciadas para um público específico e não para todos os stakeholders, fato que reduz a transparência dos relatórios e, principalmente, da informação evidenciada.

\section{MÉTODO DE PESQUISA}

Para atender ao objetivo proposto, foi utilizada a metodologia da análise de conteúdo nos relatórios da administração, notas explicativas e nos relatórios de informações ambientais contidos no relatório de Informações Anuais (IAN). Esses relatórios foram escolhidos por serem considerados instrumentos mais utilizados para esse tipo de evidenciação (Abreu et al 2009). Realizou-se a pesquisa em 154 empresas de capital aberto no período de 2006 a 2010.

As empresas foram classificadas de acordo com Brasil (2001), em baixo, médio e alto impacto ambiental. Para obter uma proxy da divulgação ambiental, estabeleceu-se a seguinte estrutura para análise:

Modelo de disclosure: qualitativo, quantitativo não-monetário, quantitativo monetário e quantitativo monetário e não-monetário, e;

Classe e subclasse: este item foi realizado com base no estudo de Nossa (2002) e Farias e Ribeiro (2009). 


\begin{tabular}{|c|c|}
\hline Classe & Subclasse \\
\hline $\begin{array}{l}\text { Investimentos, financiamentos } \mathrm{e} \\
\text { risco }\end{array}$ & $\begin{array}{l}\text { - Investimentos: Investimentos realizados pela empresa, que têm impacto } \\
\text { no gerenciamento ambiental de suas atividades, assim como em projetos } \\
\text { ambientais voltados para a comunidade externa; } \\
\text { - } \quad \text { Custos operacionais } \\
\text { - } \quad \text { Investimentos futuros } \\
\text { - } \quad \text { Financiamentonto para investimentos } \\
\text { - Passivo ambiental } \\
\text { - Riscos provisionados de natureza ambiental } \\
\text { - Riscos de litígios: riscos de possíveis litígios; } \\
\text { - Provisão para despesas futuras: relacionadas ao gerenciamento } \\
\text { ambiental ou a projetos ambientais voltados a comunidade externa. }\end{array}$ \\
\hline $\begin{array}{l}\text { Conformidade de leis } \quad \text { e } \\
\text { regulamentos }\end{array}$ & $\begin{array}{l}\text { - } \quad \text { Litígios, atuais e potenciais } \\
\text { - } \quad \text { Oultas } \\
\text { - } \quad \text { Aç razãens para cumprir: imposições dos órgãos reguladores para empresas, } \\
\text { - } \quad \text { Incidentes ambientais ocorridos } \\
\text { - } \\
\text { Regulamentos e legislações futuras: a preparação da companhia para } \\
\text { acompanhar as regulamentações e legislações futuras ou ainda quando já } \\
\text { há evidências de sua publicação em breve. }\end{array}$ \\
\hline Redução da poluição & $\begin{array}{ll}\text { - } & \text { Emissão de poluentes } \\
\text { - } & \text { Descarga/ Descarte } \\
\text { - } & \text { Gerenciamento de resíduos } \\
\text { - } & \text { Instalações e controle de processos } \\
\text { - } & \text { Ruídos e odores }\end{array}$ \\
\hline Desenvolvimento sustentável & $\begin{array}{ll}- & \text { Conservação de recursos naturais } \\
\text { - } & \text { Reciclagem } \\
\text { - } & \text { Desenvolvimento de produtos ecológicos }\end{array}$ \\
\hline Energia & $\begin{array}{ll} & \text { Uso eficiente no processo industrial } \\
- & \text { Uso de resíduos materiais para a produção de energia } \\
\text { - } & \text { Economia de energia pela reciclagem de produtos } \\
\text { - } & \text { Esforço para a redução de consumo de energia. }\end{array}$ \\
\hline $\begin{array}{lll}\text { Sistema } & \text { de } & \text { gerenciamento } \\
\text { ambiental: } & & \end{array}$ & $\begin{array}{l}\text { - } \quad \text { Política ambiental ou preocupação da companhia em relação ao meio } \\
\text { ambiente } \\
\text { - } \quad \text { Sistema de gerenciamento ambiental } \\
\text { Auditoria ambiental: a adoção de auditoria ambiental interna ou externa } \\
\text { - } \text { para certificações } \\
\text { - } \quad \text { Petas e objetivos } \\
\text { - } \quad \text { Departamento, grupo e comitê: presença na estrutura organizacional de } \\
\text { uma diretoria, departamento, comite, grupo que trate das questões } \\
\text { relacionadas ao meio ambiente; } \\
\text { - Série ISO 14000 } \\
\text { Engajamento da empresa em organizações de qualquer esfera (federal, } \\
\text { estadual ou municipal), nacionais ou internacionais, responsáveis pelo } \\
\text { estabelecimento de padrões ambientais de identificação, mensuração ou } \\
\text { de divulgação } \\
\text { Envolvimento em organizações ambientais } \\
\text { - Projetos conjuntos com outras entidades para o gerenciamento ambiental } \\
\text { Projetos desenvolvidos pela empresa e outros parceiros para o } \\
\text { gerenciamento ambiental de suas atividades. }\end{array}$ \\
\hline Outras informações ambientais & $\begin{array}{ll} & \text { Educação ambiental (para funcionários ou para a comunidade) } \\
\text { - } & \text { Incentivos e apoio a pesquisas ambientais. }\end{array}$ \\
\hline
\end{tabular}

Figura 1: Classe e subclasse

Fonte: Adaptado de Nossa (2002) e Farias e Ribeiro (2009)

Para a realização da análise de conteúdo, estabeleceram-se palavras-chave (extraídas da figura 1) com o intuito de capturar as informações ambientais evidenciadas nos relatórios e compreendeu-se em: ambiente, investimentos, impacto, multas, penalidades, corretivas, litígios, 
poluição, conservação, reciclagem, descarte, ecológico, resíduos, gerenciamento, preocupação, incentivos, sustentabilidade, instalações, redução e eficiente. Nesse processo, foram utilizados os radicais de algumas palavras com o objetivo de obter palavras derivadas, por exemplo: "ambient" que pode derivar em ambiental e ambiente.

Os relatórios do período analisado foram disponibilizados pela Bovespa no formato Word, nesse sentido, para facilitar a análise dos relatórios, foram programadas as macros do Word e Excel, em seguida deram-se os seguintes passos:

$1^{\circ}$ passo: foram acionadas as macros do Word, com o intuito de excluir as tabelas, gráficos e figuras do texto para facilitar a análise.

$2^{\circ}$ passo: o texto dos relatórios já "formatados pelas macros" foram copiados para o Excel.

$3^{\circ}$ Passo: foram acionadas as macros do Excel com a finalidade de separar a identidade da empresa, o ano do relatório e o tipo de relatório analisado, nesse momento as macros destacaram os termos chave estabelecidos para análise. Originando 28 arquivos com 50 planilhas, totalizando 1.400 planilhas. Foram analisados 2.088 relatórios de 154 companhias, obtendo 198.670 sentenças.

$4^{\circ}$ passo: analisar se as palavras-chave destacadas se referiam a informações ambientais. Nesse momento, foram definidos códigos com o intuito de facilitar a análise. Os códigos estabelecidos foram: 1 Investimentos, financiamentos e riscos; 2 Conformidade de Leis e Regulamentos; 3 Redução de poluição; 4 Desenvolvimento sustentável; 5 Energia; 6 Sistema de gerenciamento ambiental; 7 Outras informações ambientais.

Definiram-se também códigos para definir o Modelo do disclosure, sendo: 1 qualitativo, 2 para quantitativo não-monetário, o código 3 para quantitativo monetário e 4 para quantitativo monetário e não-monetário. A figura a seguir mostra alguns exemplos de disclosure ambiental encontrados na análise, como também mostra como foi feita a classificação na planilha do Modelo e Classe do disclosure, sendo:

\begin{tabular}{|c|c|c|c|c|}
\hline Modelo & Código & Classe & Código & Disclosure ambiental \\
\hline $\begin{array}{l}\text { Quantitativo } \\
\text { monetário }\end{array}$ & 3 & $\begin{array}{l}\text { Investimentos, } \\
\text { financiamentos e riscos }\end{array}$ & 1 & $\begin{array}{l}\text { Em 2006, o investimento em iniciativas } \\
\text { ambientais totalizou } R \$ 51,7 \text { milhões de } \\
\text { reais, e incluem tanto os gastos com } \\
\text { exigências legais quanto com as despesas } \\
\text { relativas a certificações }\end{array}$ \\
\hline $\begin{array}{l}\text { Quantitativo } \\
\text { monetário }\end{array}$ & 3 & $\begin{array}{l}\text { Conformidade de leis e } \\
\text { regulamentos }\end{array}$ & 2 & $\begin{array}{l}\text { “...nós estimamos que o custo total para } \\
\text { eliminar o passivo ambiental será de } \mathrm{R} \$ \\
1,2 \text { milhão..." }\end{array}$ \\
\hline Qualitativo & 1 & Redução de poluição & 3 & $\begin{array}{l}\text { Implementamos em todas as nossas } \\
\text { unidades de atendimento o Programa de } \\
\text { Gerenciamento de Resíduos de Serviços de } \\
\text { Saúde que, além dos resíduos considerados } \\
\text { infectantes, contempla o correto descarte } \\
\text { dos resíduos radioativos, químicos e lixo } \\
\text { comum. }\end{array}$ \\
\hline $\begin{array}{l}\text { Quantitativo } \\
\text { Monetário }\end{array}$ & 3 & $\begin{array}{l}\text { Desenvolvimento } \\
\text { sustentável }\end{array}$ & 4 & $\begin{array}{l}\text { O volume de recursos investidos em ações } \\
\text { externas, R\$ } 3,0 \text { milhões, foi aplicado } \\
\text { majoritariamente em ações de preservação }\end{array}$ \\
\hline Qualitativo & 1 & Energia & 5 & $\begin{array}{l}\text { As unidades industriais integradas } \\
\text { possuem matriz energética sustentada no } \\
\text { uso de recursos naturais renováveis e são } \\
\text { autossuficientes na geração de energia } \\
\text { elétrica. }\end{array}$ \\
\hline Qualitativo & 1 & $\begin{array}{l}\text { Sistema } \\
\text { gerenciamento ambiental }\end{array}$ & 6 & $\begin{array}{l}\text { Em 2009, foi realizado diagnóstico } \\
\text { ambiental nas Unidades de Utinga, } \\
\text { Capuava e Serra da Eluma, visando a } \\
\text { certificação } \\
\text { ISO-14000, norma }\end{array}$ \\
\hline
\end{tabular}




\begin{tabular}{|l|l|l|l|l|}
\hline & & & & $\begin{array}{l}\text { internacional, que estabelece as diretrizes } \\
\text { básicas para a gestão ambiental na } \\
\text { empresa }\end{array}$ \\
\hline Qualitativo & 1 & $\begin{array}{l}\text { Outras informações } \\
\text { ambientais }\end{array}$ & 7 & $\begin{array}{l}\text { O sistema implantado tem como base o } \\
\text { treinamento intensivo e constante dos } \\
\text { funcionários e colaboradores terceirizados, } \\
\text { de modo a conscientizá-los e capacitá-los a } \\
\text { desenvolver atitudes benéficas de } \\
\text { preservação e de respeito ao meio } \\
\text { ambiente }\end{array}$ \\
\hline
\end{tabular}

Figura 2: Disclosure ambiental

Fonte: Elaborado pela autora

Em seguida, após a classificação das sentenças, foi somada a quantidade de informações de cada Modelo e de cada Classe, com o intuito de obter o nível de informações ambientais das empresas brasileiras. Na etapa seguinte, realizaram-se as combinações de Modelos e Classes, objetivando verificar a quantidade e o tipo de informação evidenciada pelas companhias, para tanto, as combinações foram feitas do seguinte modo:

Figura 3: Combinações
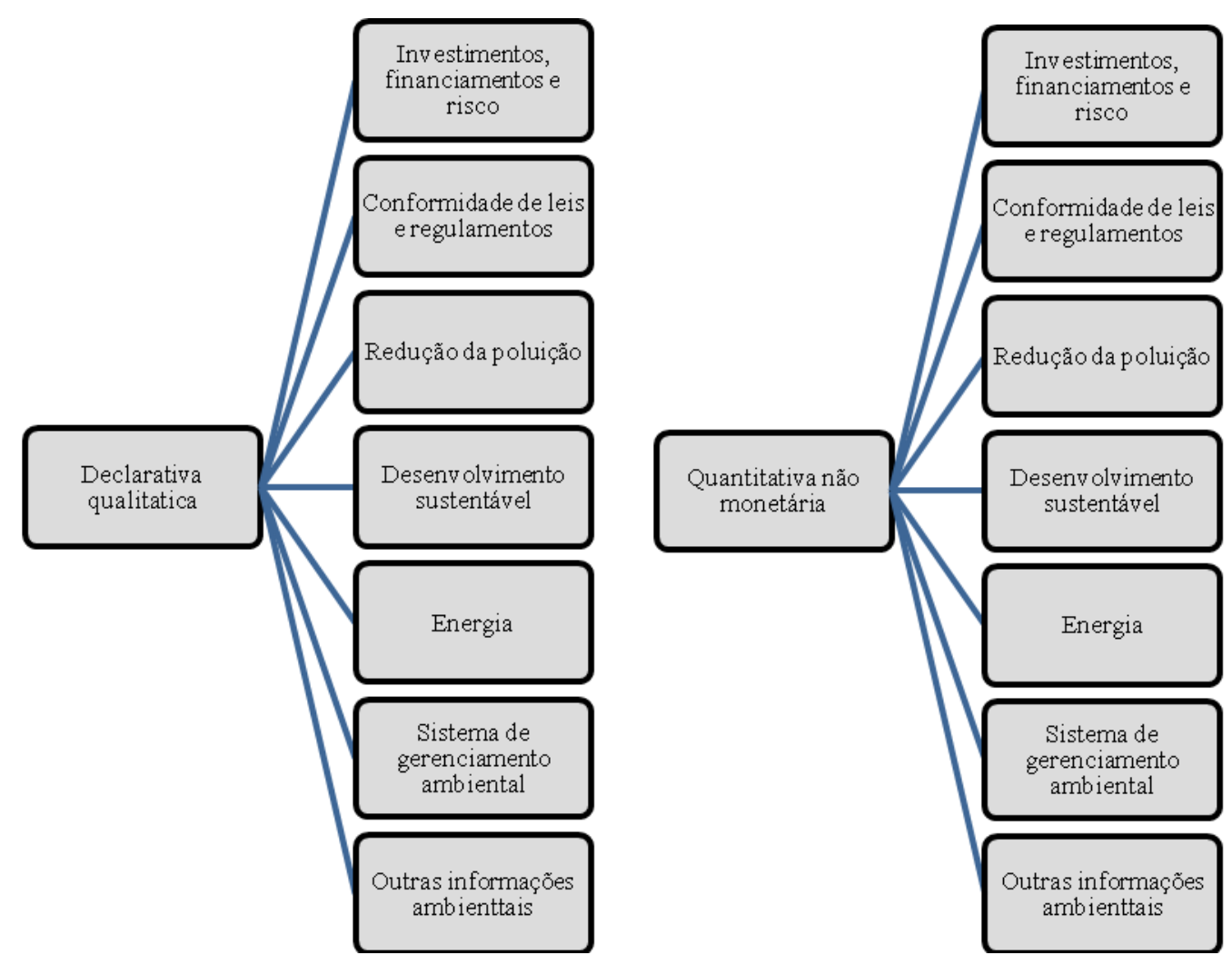


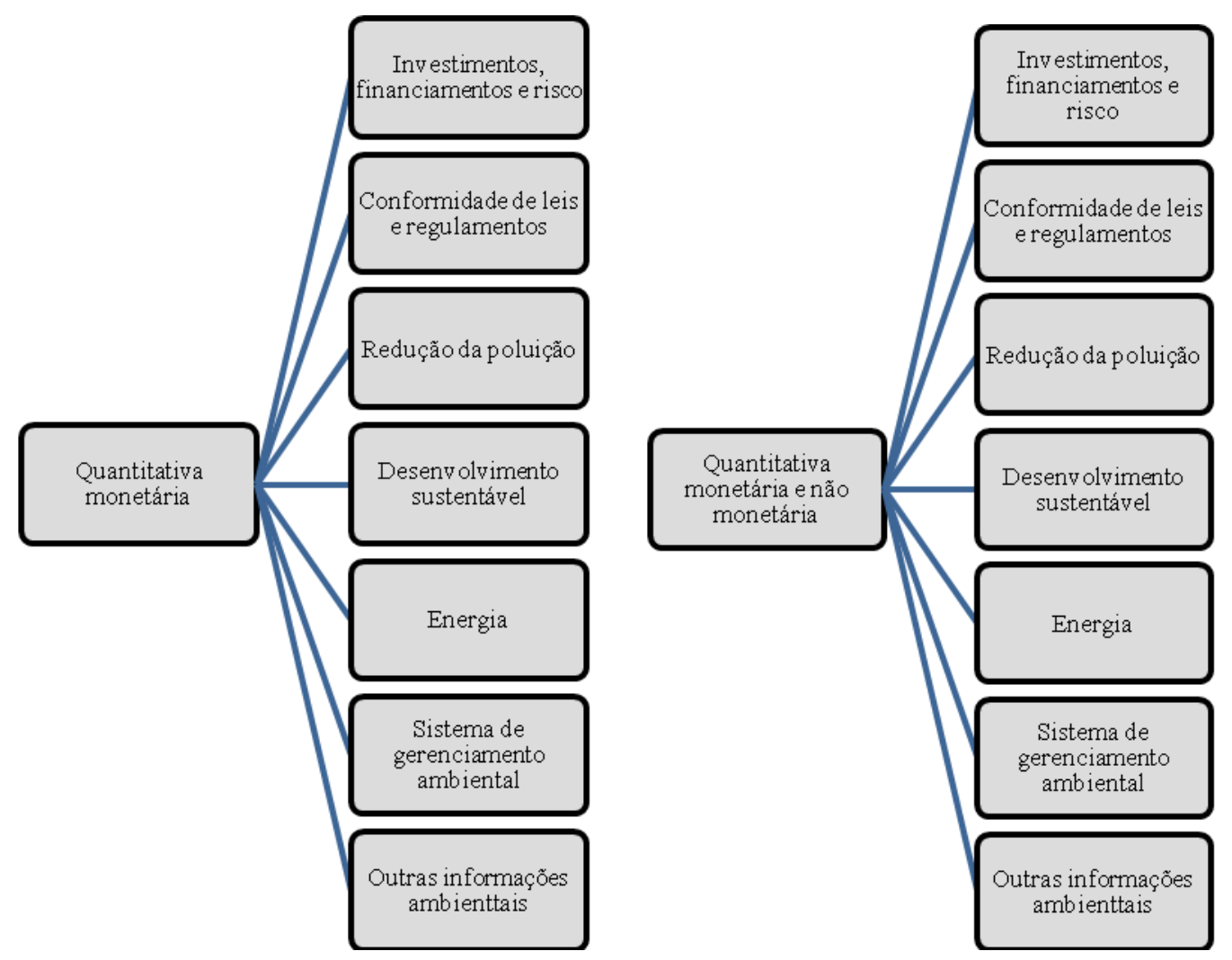

Fonte: Elaborado pela autora

Como foi mencionado anteriormente, foi definido o código de 1 ao 4 para classificar o

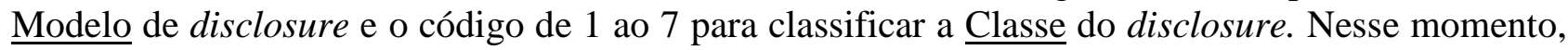
para obter as combinações do Modelo e da Classe, juntaram-se os códigos feitos na análise manual da planilha, de acordo com os exemplos a seguir:

\section{Exemplo 1:}

Modelo: Informação Qualitativa: M 1

Classe: Investimentos, Financiamentos e Risco: C 1

Combinação: M1C1

Exemplo 2:

Modelo: Informação Qualitativa: M 2

Classe: Conformidade de Leis e Regulamentos: C 2

Combinação: $\mathrm{M} 2 \mathrm{C} 2$

Exemplo 3:

Modelo: Informação Quantitativa não Monetária: M2

Classe: Investimentos, Financiamentos e Risco: C 1

Combinação: $\mathrm{M} 2 \mathrm{C} 1$

Em seguida, após a junção dos Modelos e Classes realizou-se a somatória para obter o nível e o tipo de informação evidenciado pelas companhias.

$\mathrm{O}$ passo seguinte foi analisar se o disclosure ambiental divulgado referia-se a informação positiva e/ou informação negativa, obteve-se, nesse momento, 7.502 informações ambientais positivas e 742 informações negativas.

\section{ANÁLISE DOS RESULTADOS}

A análise do nível de disclosure ambiental evidenciou que, no período de 2006 a 2010 , foram encontradas 198.670 sentenças nos relatórios analisados, dessas sentenças apenas 8.244 se 
referiam a informações ambientais. Os resultados mostraram que 51,48\% do disclosure ambiental concentram-se nos relatórios de informações ambientais; 40,06\%, nos relatórios da administração e $8,46 \%$, nas notas explicativas. relatórios.

A tabela 1 evidencia a quantidade de informações ambientais por modelos encontradas nos

Tabela 1: Quantidade de informações ambientais - Modelos.

\begin{tabular}{|l|c|c|}
\hline Modelo de disclosure ambiental & Quantidade de informações & \% \\
\hline Qualitativo & 6.798 & $11 \%$ \\
\hline Quantitativo não-monetário & 924 & $5 \%$ \\
\hline Quantitativo Monetário & 431 & $1 \%$ \\
\hline Quantitativo Monetário e não-monetário & 91 & $\mathbf{1 0 0 \%}$ \\
\hline Total & $\mathbf{8 . 2 4 4}$ & \\
\hline
\end{tabular}

Fonte: Elaborada pela autora

A Tabela 1 evidencia que $82 \%$ do disclosure ambiental que se destaca nos relatórios financeiros referem-se a informações qualitativas, seguidas das informações quantitativas nãomonetárias $11 \%$; das informações monetárias $5 \%$ e das informações monetárias e não-monetárias 1\%. A Tabela 2 mostra a quantidade de informações ambientais por classe encontradas nos relatórios.

Tabela 2: Quantidade de informação ambiental por classe.

\begin{tabular}{|l|c|c|}
\hline Classe de disclosure ambiental & Quantidade de informações & \% \\
\hline Investimentos, financiamentos e riscos & 740 & $7 \%$ \\
\hline Conformidade de leis e regulamentos & 595 & $30 \%$ \\
\hline Redução de poluição & 2510 & $21 \%$ \\
\hline Desenvolvimento sustentável & 1714 & $3 \%$ \\
\hline Energia & 231 & $22 \%$ \\
\hline Sistema de gerenciamento ambiental & 1759 & 8 \\
\hline Outras informações ambientais & 695 & $\mathbf{1 0 0}$ \\
\hline Total & $\mathbf{8 . 2 4 4}$ & \\
\hline
\end{tabular}

Fonte: Elaborada pela autora

Percebe-se, na Tabela 2, que o disclosure ambiental das empresas em análise concentra-se na redução de poluição, sendo obtidas 2.510 sentenças. Foram encontradas também 1.759 sentenças relativas ao sistema de gerenciamento ambiental; 1.714 , referentes ao desenvolvimento sustentável; 695, sobre outras informações ambientais (nesta classe inclui a educação ambiental para funcionários/ comunidade e investimentos em pesquisas ambientais); 740 sentenças referentes a investimentos financiamentos e riscos; 595 sobre conformidade de leis e regulamentos e 231 sobre o uso sustentável da energia.

Para compor a análise, fez-se ainda as combinações do Modelo e Classe de disclosure com o intuito de averiguar o tipo de informação ambiental evidenciado nos relatórios financeiros, conforme demonstra as Tabelas 3,4,5 e 6 . 
Tabela 3: Combinação do modelo qualitativo com as classes de disclosure ambiental

\begin{tabular}{|c|c|c|c|}
\hline Modelo & Classe & $\begin{array}{c}\text { Quantidade de relatórios com } \\
\text { disclosure }\end{array}$ & $\%$ \\
\hline \multirow{7}{*}{ Qualitativo } & $\begin{array}{l}\text { Investimentos, } \\
\text { financiamentos e riscos. }\end{array}$ & 562 & 6.81 \\
\hline & $\begin{array}{l}\text { Conformidade de leis } \mathrm{e} \\
\text { regulamentos. }\end{array}$ & 446 & 5.41 \\
\hline & Redução de poluição. & 2007 & 24.34 \\
\hline & $\begin{array}{l}\text { Desenvolvimento } \\
\text { sustentável. }\end{array}$ & 1331 & 16.15 \\
\hline & Energia & 159 & 1.92 \\
\hline & $\begin{array}{l}\text { Sistema de gerenciamento } \\
\text { ambiental. }\end{array}$ & 1694 & 20.55 \\
\hline & $\begin{array}{l}\text { Outras informações } \\
\text { ambientais. }\end{array}$ & 600 & 7.27 \\
\hline $\begin{array}{l}\text { Total de disclosure } \\
\text { qualitativo }\end{array}$ & & 6.799 & 82.47 \\
\hline $\begin{array}{l}\text { Total de disclosure } \\
\text { ambiental }\end{array}$ & & 8244 & 100 \\
\hline
\end{tabular}

Fonte: Elaborada pela autora

A Tabela 3 mostra que a maior parte do disclosure ambiental, evidenciado pelas companhias brasileiras, se refere a informações qualitativas, sendo a maior parte relacionada a redução de poluição e ao sistema de gerenciamento ambiental adotado pela companhia, mostrando a necessidade das empresas evidenciar a adoção de práticas ambientais nos processos administrativos e operacionais, visando a redução e/ou eliminação dos impactos. Segundo Klassen e McLaughlin (1996) e Reis (2002) as empresas tendem a evidenciar informações que visem o bem-estar do meio ambiente como o sistema de gerenciamento ambiental e métodos de redução de poluição, pois tendem a aumentar sua credibilidade e alavancar seu valor no mercado. Nesse sentido, a adoção de práticas pró-ativa favorece a redução dos custos e a divulgação dessas práticas beneficia a imagem da empresa, influenciando no desempenho financeiro da companhia.

Tabela 4: Combinação do modelo quantitativo não monetário com as classes de disclosure ambiental.

\begin{tabular}{|c|c|c|c|}
\hline Modelo & Classe & Quantidade de disclosure & $\%$ \\
\hline \multirow{7}{*}{$\begin{array}{l}\text { Quantitativo não- } \\
\text { monetário }\end{array}$} & $\begin{array}{l}\text { Investimentos, } \\
\text { financiamentos e riscos }\end{array}$ & 44 & 0.53 \\
\hline & $\begin{array}{l}\begin{array}{l}\text { Conformidade de leis } \mathrm{e} \\
\text { regulamentos }\end{array} \\
\end{array}$ & 41 & 0.49 \\
\hline & Redução de poluição & 381 & 4.62 \\
\hline & Desenvolvimento sustentável & 297 & 3.60 \\
\hline & Energia & 67 & 0.81 \\
\hline & $\begin{array}{l}\text { Sistema de gerenciamento } \\
\text { ambiental }\end{array}$ & 32 & 0.38 \\
\hline & $\begin{array}{l}\text { Outras informações } \\
\text { ambientais }\end{array}$ & 61 & 0.74 \\
\hline $\begin{array}{l}\text { Total de disclosure } \\
\text { Quantitativo não-monetário }\end{array}$ & & 923 & 11.19 \\
\hline $\begin{array}{l}\text { Total de disclosure } \\
\text { ambiental }\end{array}$ & & 8244 & 100 \\
\hline
\end{tabular}

Fonte: Elaborada pela autora

$\mathrm{Na}$ Tabela 4, percebe-se uma redução considerável de informações ambientais quantitativas não-monetárias, sendo apenas $11.19 \%$ de todo o disclosure ambiental encontrado. 
Tabela 5: Combinação do modelo quantitativo monetário com as classes de disclosure ambiental.

\begin{tabular}{|c|c|c|c|}
\hline Modelo & Classe & Quantidade de disclosure & $\%$ \\
\hline \multirow{7}{*}{ Quantitativo monetário } & $\begin{array}{l}\text { Investimentos, } \\
\text { financiamentos e riscos }\end{array}$ & 116 & 1.40 \\
\hline & $\begin{array}{l}\text { Conformidade de leis } \mathrm{e} \\
\text { regulamentos }\end{array}$ & 100 & 1.21 \\
\hline & Redução de poluição & 85 & 1.03 \\
\hline & Desenvolvimento sustentável & 71 & 0.86 \\
\hline & Energia & 5 & 0.06 \\
\hline & $\begin{array}{l}\text { Sistema de gerenciamento } \\
\text { ambiental }\end{array}$ & 29 & 0.35 \\
\hline & $\begin{array}{ll}\text { Outras } & \text { informações } \\
\text { ambientais }\end{array}$ & 25 & 0.30 \\
\hline $\begin{array}{l}\text { Total de disclosure } \\
\text { quantitativo monetário }\end{array}$ & & 431 & 5.22 \\
\hline $\begin{array}{l}\text { Total de disclosure } \\
\text { ambiental }\end{array}$ & & 8244 & 100 \\
\hline
\end{tabular}

Fonte: Elaborada pela autora

A Tabela 5 evidencia que $5.22 \%$ do disclosure ambiental encontrado destina-se a mostrar informações quantitativas monetárias, e entre as combinações de disclosure analisadas as que mais se evidenciaram nos relatórios foram os investimentos, financiamentos e riscos.

Tabela 6: Combinação do modelo quantitativo não-monetário e monetário com as classes de disclosure ambiental

\begin{tabular}{|c|c|c|c|}
\hline Modelo & Classe & Quantidade de disclosure & $\%$ \\
\hline \multirow{7}{*}{$\begin{array}{l}\text { Quantitativo não- } \\
\text { monetário e monetário }\end{array}$} & $\begin{array}{l}\text { Investimentos, } \\
\text { financiamentos e riscos }\end{array}$ & 17 & 0.20 \\
\hline & $\begin{array}{l}\text { Conformidade de leis } \mathrm{e} \\
\text { regulamentos }\end{array}$ & 8 & 0.09 \\
\hline & Redução de poluição & 37 & 0.44 \\
\hline & Desenvolvimento sustentável & 15 & 0.18 \\
\hline & Energia & 0 & 0 \\
\hline & $\begin{array}{l}\text { Sistema de gerenciamento } \\
\text { ambiental }\end{array}$ & 4 & 0.04 \\
\hline & $\begin{array}{l}\text { Outras informações } \\
\text { ambientais }\end{array}$ & 10 & 0.12 \\
\hline $\begin{array}{l}\text { Total de disclosure } \\
\text { quantitativo não-monetário } \\
\text { e monetário }\end{array}$ & & 91 & 1.10 \\
\hline $\begin{array}{l}\text { Total de disclosure } \\
\text { ambiental }\end{array}$ & & 8244 & 100 \\
\hline
\end{tabular}

Fonte: Elaborada pela autora

Na Tabela 6, percebe-se que $91 \%$ das informações encontradas são destinadas a informar dados quantitativos não-monetários e monetários, sendo a maior evidência $(0.44 \%)$ relacionada a redução de poluição.

Os dados evidenciados nas Tabelas 3, 4, 5 e 6 mostraram que 82,47\% das informações ambientais evidenciadas são destinadas a divulgar informações qualitativas e 17,53\% foram distribuídos entre as informações quantitativas não-monetárias e monetárias. Esses resultados corroboram o estudo de Calixto (2007) que analisou a evidenciação de informações ambientais no período de 1997 a 2005 e concluiu que a maior partes das empresas brasileiras evidenciam informações qualitativas e percebeu-se que é crescente esse tipo de diclosure nos relatórios financeiros. 
No âmbito internacional, o resultado também foi semelhante, O'Donovan e Gibson (2000) e Gadene e Zaman (2001), analisaram o nível do diclosure ambiental das empresas australianas e o achados evidenciaram a predominância de informações qualitativas. Segundo Alberton (2003), a profundidade do disclosure divulgado influencia a qualidade da informação, percebeu-se na análise dos resultados que o disclosure ambiental qualitativo é mais detalhado do que a informação quantitativa.

Analisou-se também a quantidade de informações ambientais positivas e negativas nos relatórios, conforme demonstra a Figura 4.

Figura 4: Tipo do disclosure ambiental

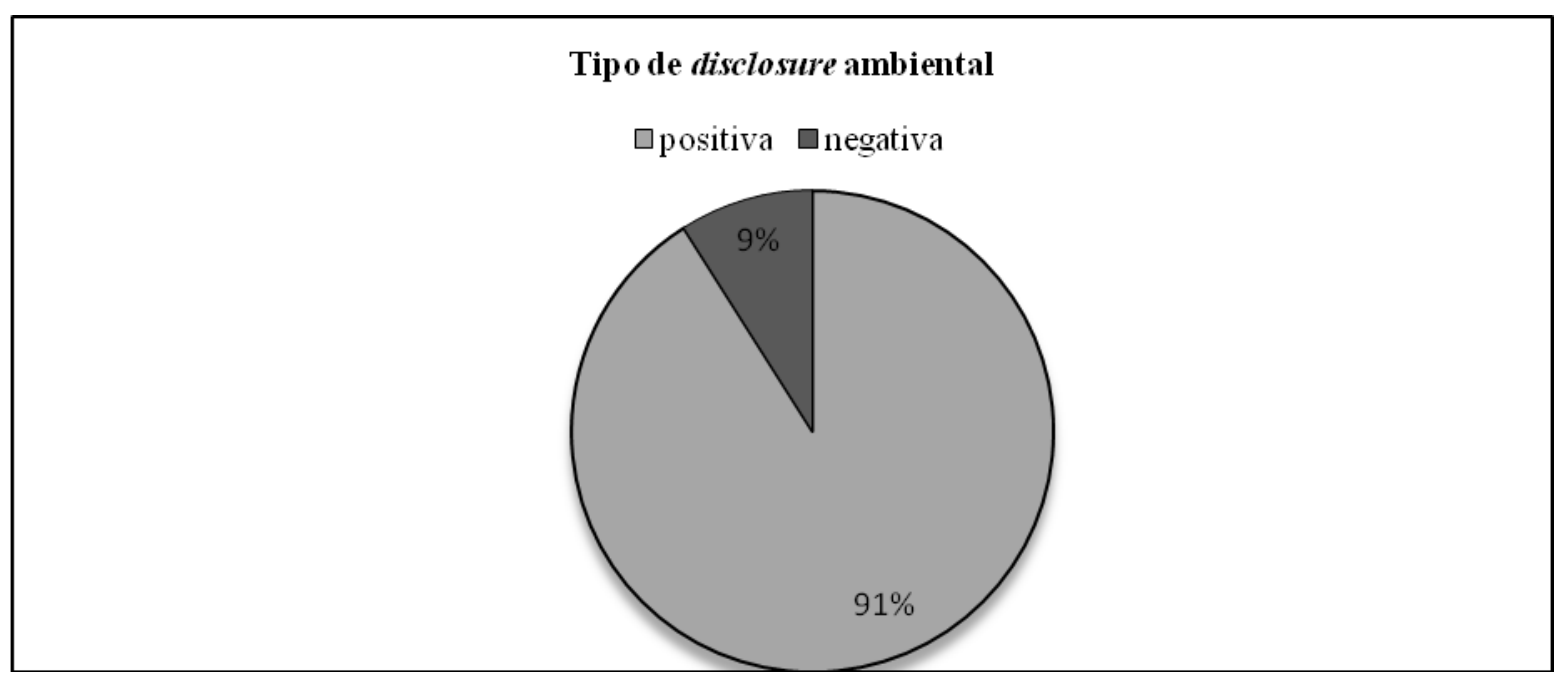

Fonte: Elaborada pela autora

Percebe-se na Figura 4 que a maior parte do disclosure ambiental, evidenciado nos relatórios financeiros, refere-se a informações positivas, ou seja, das 8.244 sentenças ambientais encontradas 7.502 são positivas e apenas 742 se referem a informações negativas.

Esse resultado corrobora o estudo de Verrechia (2001) que informa a opção do gestor em divulgar o tipo e a qualidade do disclosure voluntário, podendo aumentar e/ou mitigar o tipo de informação divulgada, esse fato influencia a qualidade da informação, uma vez que o gestor fornece aos shareholders uma visão contrária da companhia.

\section{CONSIDERAÇÕES FINAIS}

Este estudo objetivou analisar o nível do disclosure ambiental das companhias brasileiras no período de 2006 a 2010. Utilizou-se, como metodologia, a análise de conteúdo nos relatórios da administração, notas explicativas e nos relatórios de informações ambientais. A amostra compreendeu as empresas classificadas em baixo, médio e alto impacto ambiental definido por Brasil (2001), nesse sentido foram analisadas 154 companhias.

Os resultados obtidos corroboram os estudos que encontraram evidências de que é crescente a divulgação de informações ambientais qualitativas nos relatórios financeiros, com destaque para as informações relacionadas ao sistema de gerenciamento ambiental, pode-se inferir, com base na literatura analisada, que esse tipo de evidenciação pode ser estratégia da companhia em auferir melhores índices financeiros, tanto pela redução dos custos quanto pelo aumento do valor da empresa no mercado. No entanto, percebeu-se ainda que é pequena a quantidade de informação ambiental evidenciada, pois entre 198.670 sentenças encontradas 8.244 se referiam a informações 
ambientais. Os resultados demonstraram que 51,48\% do disclosure ambiental concentra-se nos relatórios de informações ambientais; 40,06\%, nos relatórios da administração e 8,46\%, nas notas explicativas.

A análise demonstrou que predomina, nos relatórios analisados, a informação ambiental qualitativa, corroborando os estudos nacionais e internacionais, tais como os de Klassen, McLaughlin (1996); O’Donovan, Gibson (2000); Gadene, Zaman (2001); Reis (2002); Calixto (2007) que encontraram evidências do crescimento da informação voluntária qualitativa nos relatórios divulgados pelas empresas.

De acordo com Alberton (2003), a qualidade da informação está vinculada à profundidade da informação, desse modo, o crescimento das informações ambientais meramente qualitativas interfere na transparência da companhia, pois impossibilita conhecer, por exemplo, os valores investidos em sustentabilidade ambiental, bem como a evolução desses investimentos no decorrer do tempo; outro fator deve-se a mensuração dos passivos ambientais das empresas, multas, ações corretivas, entre outros.

Foram encontradas 7.502 sentenças ambientais positivas e 742 sentenças ambientais negativas. Nesse sentido, pode-se inferir que predomina nas empresas analisadas o disclosure ambiental positivo. Esse resultado confirma a teoria dos disclosure voluntário, defendida por Verrechia (2001) e Dye (2001), no qual afirma que os gestores podem escolher o tipo de informação a ser evidenciada nos relatórios, e a tendência é divulgar informações que valorizam a companhia, pois buscam auferir melhores resultados financeiros com a imagem da empresa, uma vez que há evidências na literatura que o mercado reage negativamente com a divulgação de informações ambientais ruins, ou seja, o mercado premia as empresas que evidenciam informações ambientais positivas e penaliza as empresas que evidenciam informações ambientais ruins. Esses fatores influenciam os gestores a divulgar e, em vários casos, amplificar a informação ambiental positiva com o intuito de minimizar os riscos percebidos pelo mercado.

A principal limitação da pesquisa foi a reduzida quantidade de informação ambiental divulgada ou a falta de informação ambiental evidenciada nos relatórios analisados. Além disso, a baixa qualidade da informação, uma vez que a maioria das sentenças classificadas se refere a dados qualitativos e poucos são os dados quantitativos.

Sugere-se, em estudos futuros, verificar se o disclosure ambiental (positivo e negativo) influencia no risco da empresa, utilizar o beta como proxy para o risco. Sugere-se também verificar se o disclosure ambiental está relacionado a determinantes, tais como tamanho da companhia, setor, origem do controle acionário (nacional ou estrangeiro) e governança corporativa.

\section{REFERÊNCIAS}

Abreu, M.C., Sá de et al.( jan./mar. 2009.) Efeito da conduta social sobre a performance econômica: evidências da indústria têxtil brasileira: Revista Contabilidade Vista e Revista, Universidade Federal de Minas Gerais, Belo Horizonte, 20(1), 119-142.

Alberton, A.(2003) Meio ambiente e desempenho econômico-financeiro: o impacto da ISO 14001 nas empresas brasileiras. 2003. Tese (Doutorado) - Programa de Pós-Graduação da Universidade Federal de Santa Catarina (UFSC), Florianópolis.

Alrazi, B., Sulaiman, M., Ahmad, N.N.N. A longitudinal examination of environmental reporting Practices in Malaysia. Gadjah Mada International Journal of Business, 11(1).

Borba, J.A., Rover, S., Dal-Ri Murcia, F.(2009) Características do disclosure ambiental de empresas brasileiras potencialmente poluidoras: uma análise das demonstrações financeiras e dos relatórios de sustentabilidade do período de 2005 a 2007. 1st South American Congress on Social and Environmental Accounting Research - CSEAR. Universidade Federal do Rio de Janeiro - $27 \mathrm{e}$ 28/07/2009 - Rio de Janeiro - RJ - Brasil. 
Brasil(2001) Ministério de Meio Ambiente. Lei $N^{\circ}$ 10.165, de 27 de dezembro de 2000. Altera a Lei $\mathrm{n}^{\mathrm{o}}$ 6.938, de 31 de agosto de 1981, que dispõe sobre a Política Nacional do Meio Ambiente, seus fins e mecanismos de formulação e aplicação, e dá outras providências. Brasília: Senado Federal. Recuperado em 18 jul.2010, de: 〈http://www.planalto.gov.br/ccivil_03/Leis/L10165.htm>.

Calixto, L. (jan/jun - 2007) Uma análise da evidenciação ambiental de companhias brasileiras - de 1997 a 2005. Revista UnB Contábil - UnB, Brasília, 10(1).

Costa, G. Torres, M. I. da., Alessandra V., Silva, L. (2011). Análise do conteúdo dos relatórios de sustentabilidade de empresas premiadas por suas práticas de responsabilidade socioambiental. Simpósio de Administração da Produção, Logística e Operações Internacionais. SIMPOI, 14. Recuperado em 02/09/2011, de: http://www.simpoi.fgvsp.br/arquivo/2011/artigos/E2011_T00329_PCN60101.pdf

Costa, R.S. da, Marion, J.C. R. ( Jan./Abr. 2007) Cont. Fin. USP, São Paulo, 43, 20 - 33.

Costa, R.S. da, Marion, J.C. A (2007) uniformidade na evidenciação das informações ambientais. Revista Contabilidade e Finanças, (43), 20-33.

Clarkson, P.M., LI, Y., Richardson, G.D., Vasvari; Florin P. (2006). Revisiting the relation between environmental performance and environmental disclosure: an empirical analysis. Recuperado em: 9 out. 2011, de http://papers.ssrn.com/sol3/papers.cfm?abstract_id=899974

Cunha, J.V.A. da, Ribeiro, M. de S.(jan/jun.2008) Divulgação voluntária de informações de natureza social: um estudo nas empresas brasileiras. R.Adm. Eletrônica, Revista de Administração Eletrônica (RAE). São Paulo, 1(1), art.6.

Dal-Ri Murcia, F., Santos, A. dos. (maio/ago. 2009) Fatores determinantes do nível de disclosure voluntário das companhias abertas no Brasil. REPeC - Revista de Educação e Pesquisa em Contabilidade, Brasília, 3(2), art. 4, 72-95.

Da-Ri Murcia, F., Rover, S., Lima, I., Fávero, L.P.L., Lima, G., Sampaio F.A. de.( jan/dez. 2008) 'Disclosure verde' nas demonstrações contábeis: características da informação ambiental e possíveis explicações para a divulgação voluntária. Revista UnB Contábil, 11(1-2).

Dye, R.E.( Spring 1985) Disclosure of nonproprietary information. Journal of Accounting Research, 23(1), 123-145.

DYE, R. (2001) An evaluation of "essays on disclosure" and the disclosure literature in accounting. Journal of Accounting and Economics, 32, 181-235.

Farias, K. T. R. , Ribeiro, M. S. (2009). A relação entre divulgação ambiental, desempenho ambiental e desempenho econômico nas empresas brasileiras de capital aberto: uma pesquisa utilizando equações simultâneas. In: International Accounting Congress - Iaeer, São Paulo. Accounting internationalization: current and future trends.

Ho, L-C.J.; Taylor, M.(2007) An empirical analysis of triple bottom-line reporting and its determinants: evidence from the United States and Japan. The Journal of International Financial Management and Accounting, 18(2), 123-150.

Klassen, R.D., MClaughlin, C.P. (1996) The impact of environmental management on firm Performance. Management Science, 42(8), 1199-1214.

Lima, G.A.S.F. de. (janeiro/abril 2009) Nível de evidenciação $\times$ custo da dívida das empresas brasileiras. Revista Contabilidade \& Finanças, USP, São Paulo, 20(49), 95-108. 
Manurung, A.M., Basuki, H.(January-April 2010) An analytical assessment of assurance practices In social environmental and sustainable reporting In the united kingdom and north America. Gadjah Mada International Journal of Business, 12(1).

Murcia, F. D. et al.(2010) Mapeamento da pesquisa sobre disclosure ambiental no cenário internacional: uma revisão dos artigos publicados em periódicos de língua inglesa no período de 1997 a 2007. Revista ConTexto, Porto Alegre, 10(17), 7-18, $1^{\circ}$ semestre.

Nossa, V. (2002) Disclosure ambiental: uma análise do conteúdo dos relatórios ambientais de empresas do setor de papel e celulose em nível internacional. 2002. 246 f. Tese (Doutorado em Controladoria e Contabilidade) - Faculdade de Economia, Administração e Contabilidade, Universidade de São Paulo (USP), São Paulo.

O'donovan, G., Gibson, K.(2000) Environmental disclosure in the corporate annual report: a longitudinal Australian study. Corporate environmental reporting. Recuperado em 2 jul, 2011, de: $<$ www.business.vu.edu.au/accfinresearch/seminar/garyo'donovan.pdf $>$.

Reis, H. L. (2002). Os impactos de um sistema de gestão ambiental no desempenho financeiro das empresas: um estudo de caso. Anais do Encontro Nacional dos Programas de Pós-Graduação em Administração, Salvador, BA, Brasil, 26.

Salotti, B., Yamamoto, M.(2005) Ensaio sobre a teoria da divulgação. Brazilian Business Review, 2(1), 53-70.

Data do recebimento do artigo: 21/03/2012

Data do aceite de publicação: 21/08/2012 